

Review Article

\title{
Application of Next Generation Sequencing Genetic Studies of Urea Cycle Disorders
}

\author{
Nguyen Thi Thu Huong ${ }^{1,2,3}$, Nguyen Thi Kim Lien ${ }^{1,2}$, \\ Nguyen Huy Hoang ,,$* *^{*}$ \\ ${ }^{1}$ Vietnam Academy of Science and Technology, \\ 18 Hoang Quoc Viet, Hanoi, Vietnam \\ ${ }^{2}$ Graduate University of Science and Technology, \\ 18 Hoang Quoc Viet, Hanoi, Vietnam \\ ${ }^{3}$ Hong Duc University, \\ 565 Quang Trung, Thanh Hoa, Vietnam \\ Received 18 March 2021 \\ Revised 02 June 2021; Accepted 24 June 2021
}

\begin{abstract}
Urea cycle disorder is a group of rare, inherited metabolic disorders in the pathway transforming ammonia to urea. The mutations in genes coding for 6 enzymes that are participated including carbamoyl phosphate synthase I (CPSI), ornithine transcarbamylase (OTC), argininosuccinate synthase (ASS1), argininosuccinate lyase (ASL), arginase (ARG1), and N-acetyl glutamate synthase (NAGS), and 2 transport systems ((ornithine translocase (ONT1), citrin)) in the urea cycle are responsible for ammonia accumulation in the blood. Hyperammonemia is the cause of severe neurological symptoms and even death. In almost all cases, clinical examinations and biochemical experiments are necessary, but insufficient information for an accurate diagnosis. Mutation analysis is an effective method to confirm the diagnosis and could be the basis for genetic counseling. The rapid development and widely using of next generation sequencing (NGS) have brought incredible advances in molecular diagnosis of genetic diseases in general. In this article, we systematize the UCD genetic studies applying NGS method, thereby providing a basis for not only disease diagnosis but also future research.
\end{abstract}

Keyworsds: Genetic Diseases; Mutations; Next Generation Sequencing (NGS); Urea Cycle Disorder (UCD); Variantions

\footnotetext{
*Corresponding Authors

Email address: nhhoang@igr.ac.vn

https://doi.org/10.25073/2588-1140/vnunst.5196
} 


\title{
Úng dụng công nghệ giải trình tự gen thế hệ mới trong nghiên cứu di truyền bệnh rối loạn chu trình chuyển hóa urê
}

\author{
Nguyễn Thị Thu Hường ${ }^{1,2,3}$, Nguyễn Nguyễn Thị Kim Liên ${ }^{1,2}$, \\ Nguyễn Huy Hoàng ${ }^{1, *}$ \\ ${ }^{I}$ Viện Hàn lâm Khoa học và Công nghệ Việt Nam, \\ 18 Hoàng Quốc Việt, Hà Nội, Việt Nam \\ ${ }^{2}$ Họ viên Khoa học và Công nghệ Việt Nam \\ 18 Hoàng Quốc Việt, Hà Nội, Việt Nam \\ ${ }^{3}$ Đai Học Hồng Đî́c \\ 565 Quang Trung - Phường Đông Vệ - Tp.Thanh Hóa \\ Nhận ngày 18 tháng 3 năm 2021 \\ Chỉnh sửa ngày tháng năm ; Chấp nhận đăng ngày tháng năm 2021
}

\begin{abstract}
Tóm tắt: Rối loạn chu trình chuyển hóa urê (UCD) là rối loạn chuyển hóa bẩm sinh, hiếm gặp, gây ra do đột biến trên các gen mã hóa cho 6 enzyme: carbamoyl phosphate synthase I (CPSI), ornithine transcarbamylase (OTC), argininosuccinate synthase (ASS1), argininosuccinate lyase (ASL), arginase (ARG1), N-acetyl glutamate synthase (NAGS) và 2 hệ thống vận chuyển, ornithine translocase (ONT1), citrin, của chu trình chuyển hóa urê. Sự ứ đọng amoniac là nguyên nhân dẫn đến các triệu chứng thần kinh nghiêm trọng, thậm chí tử vong. Các thăm khám lâm sàng, xét nghiệm hóa sinh là cần thiết, nhưng chưa đủ thông tin để đưa ra chần đoán chính xác. Phân tích đột biến là phương pháp hữu hiệu để phát hiện bản chất di truyền của bệnh từ đó đưa ra chẩn đoán xác định. Sự phát triển nhanh chóng của phương pháp giải trình tự gen thế hệ mới (NGS) mang đến nhiều tiến bộ đáng kinh ngạc trong chẩn đoán phân tử bệnh di truyền nói chung và bệnh nhân rối loạn chu trình chuyển hóa urê nói riêng. Bài viết này hệ thống các kết quả đạt được khi sử dụng NGS trong nghiên cứu di truyền bệnh $\mathrm{UCD}$, cung cấp cơ sở cho công tác chẩn đoán và nghiên cứu.
\end{abstract}

Tù khóa: Bệnh di truyền; Biến thể ; Đột biến; Giải trình tự gen thế hệ mới (NGS); Rối loạn chu trình chuyển hóa urê (UCD)

\section{Giới thiệu}

Bệnh rối loạn chu trình chuyển hóa urê (UCD) là bệnh di truyền do các đột biến xảy ra trên các gen mã hóa cho 1 trong 6 enzyme và 2 hệ thống vận chuyển liên quan (Bảng 1) [1]. Đây là dạng bệnh hiếm gặp với tỷ lệ mắc ước tính khoảng 1/35.000 [2]. Hầu hết, các bệnh thuộc nhóm UCD đều là bệnh di truyền lặn trên nhiễm sắc thể thường ngoại trừ bệnh liên quan đến gen OTC là bệnh di truyền lặn, liên kết nhiễm sắc thể giới tính $\mathrm{X}$. Khiếm khuyết trên con đường chuyển hóa, khiến cho nitơ không thể chuyển hóa thành urê và tích lũy dưới dạng amoniac $\left(\mathrm{NH}_{3}\right)$, rất độc cho não, cản trở quá trình tạo ra năng lượng cũng như chuyển hóa bình thường của các chất dẫn truyền thần kinh. Khi nồng độ

\footnotetext{
*Tác giả liên hệ

Địa chỉ email: nhhoang@igr.ac.vn

https://doi.org/10.25073/2588-1140/vnunst.5196
} 
Bảng 1: Các bệnh thuộc nhóm rối loạn chu trình chuyển hóa urê (UCD) và các gen liên quan.

\begin{tabular}{|l|c|c|c|c|}
\hline \multicolumn{1}{|c|}{ Bệnh } & Gen & Vị trí & Exons & Kiểu di truyền \\
\hline Thiếu hụt Carbamylphosphate synthetase I & $C P S 1$ & $2 \mathrm{q} 35$ & 38 & AR \\
\hline Thiếu hụt Ornithine transcarbamylase & $O T C$ & $\mathrm{Xp} 11.4$ & 10 & X-linked \\
\hline Thiếu hụt Argininosuccinate synthetase & $A S S 1$ & $9 \mathrm{q} 34.11$ & 16 & AR \\
\hline Thiếu hụt Argininosuccinate lyase & $A S L$ & $7 \mathrm{q} 11.21$ & 17 & AR \\
\hline Thiếu hụt Arginase & $A R G 1$ & $6 \mathrm{q} 23.2$ & 8 & AR \\
\hline Thiếu hụt N-Acetyl glutamate synthase & $N A G S$ & $17 \mathrm{q} 21.31$ & 7 & AR \\
\hline Thiếu hụt Ornithine translocase & $S L C 25 A 15$ & $13 \mathrm{q} 14.11$ & 7 & AR \\
\hline Thiếu hụt Citrin & $S L C 25 A 13$ & $7 \mathrm{q} 21.3$ & 18 & AR \\
\hline
\end{tabular}

AR: Di truyền lặn trên NST thường; X-linked: Di truyền liên kết NST giới tính X.

$\mathrm{NH}_{3}$ trong máu tăng lên tới mức 100-200 $\mu \mathrm{mol} / \mathrm{L}$ (bình thường $<50 \mu \mathrm{mol} / \mathrm{L}$ ), bệnh nhân thường biểu hiện các triệu chứng như chứng thờ ơ và nôn mửa [2]. Khi nồng độ $\mathrm{NH}_{3}$ tăng cao hơn, bệnh nhân có thể bị phù não lan tỏa, hôn mê và tử vong [2]. Mức độ nghiêm trọng của bệnh phụ thuộc vào loại enzyme thiếu hụt và mức độ bất hoạt của enzyme đó [1]. Các bệnh nhân thiếu hụt nghiêm trọng hoặc mất hoàn toàn hoạt tính của các enzyme thường có biểu hiện kiểu hình nghiêm trọng [3]. Các thể bệnh nhẹ hơn thường xuất hiện ở các bệnh nhân mang đột biến gây ra thiếu hụt hoặc mất một phần hoạt tính của enzyme. Bên cạnh đó, các triệu chứng của bệnh có thể được kích hoạt do các tác nhân bên ngoài như thể trạng đau yếu hoặc stress, dẫn đến sự gia tăng nồng độ amoniac trong máu. Nếu các rối loạn chu trình urê không được phát hiện sớm và điều trị kịp thời, bệnh có thể dẫn đến các biến chứng nghiêm trọng, thậm chí đe dọa đến tính mạng [3].

Phương pháp giải trình tự truyền thống, Sanger, đã đạt được nhiều thành tựu quan trọng trong đó có thành công trong việc hoàn thành dự án hệ gen người (HGP) vào năm 2003 [4]. Tuy nhiên, dự án này cần hơn 1 thập kỷ và tiêu tốn gần 1 tỷ USD để hoàn thành. Trong những năm sau đó, mặc dù có nhiều cải tiến nhưng chi phí giải trình tự toàn bộ hệ gen vẫn còn rất đắt đỏ để có thể sử dụng thường xuyên trong thực hành lâm sàng. Ví dụ, chi phí giải trình tự toàn bộ hệ gen người vào năm 2006 ước tính khoảng 20-25 triệu USD [4].
Kể từ năm 2008, với sự ra đời của các phương pháp giải trình tự gen thế hệ mới (next generation sequencing -NGS), cho phép toàn bộ hệ gen (whole-genome sequencing - WGS) hoặc toàn bộ vùng mã hóa (whole-exome sequencing - WES) hoặc các vùng trình tự đích được giải trình tự nhanh hơn, với lượng thông tin lớn. Nhờ đó, chi phí dùng cho việc giải trình tự giảm xuống đáng kể và việc ứng dụng phương pháp này vào công tác chẩn đoán lâm sàng có tính khả thi hơn. Trong đó, phương pháp giải trình tự toàn bộ vùng mã hóa (WES) là một trong những ứng dụng của NGS đã được chứng minh là công cụ hiệu quả trong việc xác định gen gây bệnh theo di truyền Mendel do vùng mã hóa chỉ chiếm $1 \%$ hệ gen nhưng số lượng bệnh do đột biến nằm trong vùng này chiếm tới $85 \%$ [5].

\section{Phương pháp giải trình tự gen thế hệ mới}

Việc áp dụng phương pháp giải trình tự gen thế hệ mới (NGS) trong chẩn đoán bệnh di truyền lần đầu tiên vào năm 2009 là một bước tiến nhảy vọt trong cuộc cách mạng công nghệ, có ý nghĩa quan trọng đối với nghiên cứu di truyền y học [6]. NGS là một công cụ sinh học mạnh, chính xác, linh hoạt, và được sử dụng rộng rãi, sẽ cùng với phương pháp giải trình tự Sanger xây dựng các tiêu chuẩn chẩn đoán. NGS có một số ưu điểm như sau:

+ Tiêu tốn ít thời gian và rẻ tiền hơn so với phương pháp giải trình tự truyền thống Sanger. 
Phương pháp NGS có thể giải mã toàn bộ 1 bộ gen người chỉ trong 1 ngày trong khi phương pháp Sanger cần đến cả một thập kỷ [7]. Theo số liệu thống kê của Schwarze K.B và cộng sự (2020), chi phí để giải trình tự 1 bộ gen người đối với trường hợp mắc bệnh ung thư là 6841 EUR (8346 USD), đối với trường hợp mắc bệnh hiếm là 7050 EUR (8601 USD) [4].

+ Độ nhạy cao, có thể phát hiện các đột biến trên toàn hệ gen bao gồm đột biến thay thế, mất đoạn, chèn đoạn, lặp đoạn, thay đổi số lượng bản sao, đảo hoặc chuyển đoạn nhiễm sắc thế, là cơ sở để các bác sỹ đưa ra chẩn đoán nhanh từ đó quyết định liệu pháp điều trị tối ưu cho các bệnh nhân mắc bệnh di truyền [8].

+ Cần đến lượng DNA thấp hơn so với phương pháp giải trình tự DNA truyền thống.

+ Phương pháp giải trình tự gen thế hệ mới sử dụng RNA ( $N G S$-based $R N A$-Seq), có thể cung cấp toàn bộ thông tin phiên mã, không cần đến thông tin trình tự di truyền. Do vậy, phương pháp này có thể là sự thay thế tối ưu cho phương pháp microarrays trong các nghiên cứu biểu hiện gen [9].

Thập kỷ qua đã chứng kiến sự tiến bộ vượt bậc trong quá trình phát triển công nghệ giải trình tự gen vào sự cải tiến các công cụ phát hiện mới, hiệu quả đồng thời thu nhỏ các máy giải trình tự sẵn có, góp phần đáng kể vào việc nghiên cứu hệ gen. Hiện nay, hai hệ thống giải trình tự được sử dụng chủ yếu là Ion Torrent và Illumina. Máy Ion Torrent Personal Genome Machine (PGM) ra mắt vào năm 2011, trong khi các máy của Illumina được sử dụng rộng rãi cho mục đích chẩn đoán là MiSeq được bán trên thị trường vào năm 2011, máy MiniSeq được tung ra thị trường vào năm 2016, máy iSeq100 vào cuối năm 2017 [10]. Hệ thống Ion Torrent khai thác PCR nhũ tương để xác định trình tự các nucleotide thông qua việc phát tín hiệu do ion $\mathrm{H}^{+}$được giải phóng trong quá trình tổng hợp DNA bằng 1 chip silicon được cải biến. Công nghệ Illumina giải trình tự dựa trên nguyên lý tổng hợp chuỗi (Sequencing by Synthesis) bồ sung với gen đích, sử dụng các sợi liên tục rất nhỏ để giảm thời gian ghi hình ảnh đồng thời đẩy nhanh quá trình giải trình tự [10].

\section{Giải trình tự gen thế hệ mới (NGS) trong chẩn đoán bệnh rối loạn chu trình chuyển hóa urê}

Rối loạn chu trình urê (UCD) là một nhóm các bệnh rối loạn quá trình chuyển hóa nitơ dẫn đến tăng nồng độ amoniac trong máu và nước tiểu. Tuy nhiên, triệu chứng này chỉ là một dấu hiệu cơ bản đại diện cho các triệu chứng của bệnh. Trong bất kỳ trường hợp nghi ngờ nào, các xét nghiệm sinh hóa xác định sự có mặt và nồng độ amino acid trong máu là cần thiết. Tuy nhiên, nhiều loại bệnh UCD không có dấu hiệu sinh hóa nhất định. Chính vì vậy, phương pháp xét nghiệm enzyme hoặc phân tích đột biến được sử dụng để phát hiện rõ hơn nguyên nhân gây bệnh. Mặc dù vậy, các xét nghiệm enzyme thường không được khuyến cáo trong các trường hợp như bệnh thiếu hụt $\mathrm{N}$ acetylglutamate synthase (NAGS), carbamoylphosphate synthetase (CPS1) và ornithine transcarbamylase (OTC) do phải tiến hành sinh thiết gan [11]. Trong khi phương pháp giải trình tự gen sẽ giúp xác định nguyên nhân di truyền hoặc tự phát trong quá trình phát triển cơ thể. Trong nhiều năm, các đột biến được phát hiện chủ yếu bằng phương pháp giải trình tự Sanger. Tuy nhiên, phương pháp này yêu cầu phải xử lý một lượng công việc lớn, do đó tiêu tốn nhiều thời gian cũng như kinh phí. Ví dụ, nhóm nghiên cứu Ulrich Finckh (1998) đã sử dụng phương pháp Sanger để giải trình tự 11 vùng đặc hiệu của gen $C P S 1$ và phát hiện được đột biến p.T544M [12]. Laróvere, L. E. và cộng sự (2009) đã giải trình tự 16 exon của gen $A S S$ bằng phương pháp Sanger và phát hiện được một đột biến trên gen (c.1168G>A), p.G390R trong các gia đình ở một vùng có giới hạn về địa lý ở Argentina [13]. Năm 2016, Al Kaabi, E. H., \& El-Hattab, A. W. cũng đã sử dụng phương pháp này để giải trình tự các gen $C P S 1, N A G S$, OTC, ASS1, ASL, ARG1, kết hợp thăm khám lâm sàng và xét nghiệm sinh hóa để xác định một đột biến trạng thái đồng hợp tử c.1097- 
2A>T tại vị trí ghép nối trên gen $N A G S$ ở bệnh nhân nhi nữ, 2 ngày tuổi [13]. Trong những năm gần đây, phương pháp giải trình tự thế hệ mới (NGS), đã tạo ra cuộc cách mạng trong nghiên cứu hệ gen, cho phép phát hiện các đột biến một cách nhanh chóng và đáng tin cậy. Nhờ đó, phổ đột biến trên các gen liên quan đến chu trình chuyển hóa urê, gây bệnh UCD ngày càng được mở rộng.

\subsection{NGS phát hiện đột biến trên gen CPS1}

Carbamoylphosphate synthetase 1 (CPS1) là enzyme đầu tiên trong chu trình urê, xúc tác cho phản ứng tổng hợp carbamoyl phosphate từ amoniac trong cơ chất của ty thể. Gen mã hóa cho enzyme này nằm ở vị trí $2 \mathrm{q} 35$, gồm 4500 nucleotide, 38 exon mã hóa cho chuỗi polypeptide gồm 1500 amino acid [14]. Bệnh thiếu hụt CPS1, gây ra do các đột biến trên gen $C P S 1$, là một rối loạn di truyền lặn trên nhiễm sắc thể thường. Đây là một trong những bệnh thuộc nhóm UCD nghiêm trọng nhất với tỷ lệ mắc ước tính là 1/1.300.000 [15]. Hiện nay, cơ sở dữ liệu ClinVar đã cập nhật 491 đột biến gây bệnh trên gen CPSI.

Với mục đích xác định đột biến nhanh và chi phí thấp, Amstutz, U và cộng sự (2011) đã sử dụng hệ thống FLX (454 Life Sciences) để giải trình tự toàn bộ gen $O T C, C P S 1, N A G S$ của 4 mẫu DNA của các bệnh nhân được chẩn đoán mắc bệnh UCD trong đó 2 mẫu đã được xác định mang đột biến trên gen $O T C$ và 2 mẫu mang đột biến trên gen $C P S 1$ bằng phương pháp Sanger. Các đột biến phát hiện được trên 2 gen $O T C$ và $C P S$ bằng hệ thống giải trình tự toàn bộ hệ gen FLX (454 Life Sciences) là cơ sở để khẳng định giải trình tự gen thế mới là công cụ hữu hiệu để phát hiện đột biến [16]. Năm 2017, Choi và cộng sự đã công bố 1 đột biến vô nghĩa mới c.580C $>\mathrm{T}$ (p.Q194*) và 1 đột biến dịch khung cũ c.1547delG (p.G516Afs*5) ở 1 bé trai Hàn Quốc, 4 ngày tuổi với các triệu chứng suy hô hấp do bệnh não chuyển hóa, nồng độ amoniac máu tăng cao bằng giải trình tự WES [14]. Cũng bằng công nghệ này, năm 2018, các thành viên trong nhóm nghiên cứu của Zhang đã phát hiện được ba đột biến thay thế mới (c.2537C $>\mathrm{T}, \quad$ p.P846L và c.3443T $>\mathrm{A}$, p.M1148K, c.1799G >A, p.C600Y) và 1 đột biến mất đoạn đã công bố (c.4088_4099del, p.L 1363 I1366del) trên gen CPS1 ở hai trẻ sơ sinh 39 tuần tuổi, người Trung Quốc với các biểu hiện như hôn mê, bệnh não và tăng amoniac máu [17].

Sử dụng hệ thống HiSeq2000 (Illumina) để giải trình tự vùng mã hóa ở 2 bệnh nhân mắc bệnh thiếu hụt CPS1 người Trung Quốc, khởi phát sơ sinh, 3 đột biến mới bao gồm 1 đột biến thay thế (c.1981G>T, p.G661C), 1 đột biến vô nghĩa (c.2896G>T, p.E966*), 1 đột biến mất đoạn nhỏ (c.622-3C>G) và 1 đột biến thay thế cũ (c.1631C > T (p.T544M) được nhóm nghiên cứu Yang và cộng sự tìm thấy [18]. Trong số 10 đột biến được Zhou và cộng sự (2020) phát hiện bằng giải trình tự WES ở 9 bệnh nhân người Trung Quốc mắc bệnh UCD, khởi phát sơ sinh, có 4 đột biến trên gen CPS1 bao gồm 2 đột biến mới (c.2938G $>$ A, p.G980S và c.3734T $>A$, p.L1245H) và 2 đột biến đã được công bố

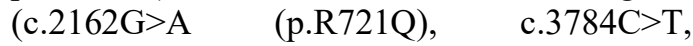
p.R1262X) [15]. Nhóm nghiên cứu của Fan (2020) đã sàng lọc được 9 đột biến trên gen CPS1 ở 5 bệnh nhân mắc bệnh thiếu hụt CPS1 bao gồm c.478G $>$ A (p.A160T), c.3949C $>\mathrm{T}$ (p.R1317W), c.3945G $>A \quad$ (p.W1315X, c. $1958 \mathrm{~T}>\mathrm{G}$ (p.V653G) c.1271A $>\mathrm{T}$ (p.E379V), c.3928C $>\mathrm{T} \quad$ (p.P1265S), c.1760G $>\mathrm{A}$ (p.R587H), c.1145C $>\mathrm{T} \quad$ (p.P382L), c.2865 c.2869delAAACT (p.T955Tfs*) [19]. Mới đây, nghiên cứu của Liu và cộng sự (2021) cũng đã phát hiện được 1 đột biến mới trên gen CPS1: c.2429A >C (p.Q810P), 3 đột biến cũ c. $2876 \mathrm{~A}>\mathrm{G}$ (p. Y959C), 2339G $>$ A (p.R780H), c. $3520 \mathrm{C}>\mathrm{T}$ (p.R1174X) ở 2 bé trai 4 và 2 ngày tuổi [20].

\subsection{NGS phát hiện đột biến trên OTC}

Ornithine transcarbamylase (OTC) là enzyme xúc tác cho phản ứng tổng hợp citrulline từ carbamoylphosphate và ornithine. Gen $O T C$ nằm trên cánh ngắn của nhiễm sắc thể 
$\mathrm{X}$, vì vậy bệnh thiếu hụt OTC là bệnh di truyền lặn, liên kết nhiễm sắc thể giới tính X. Các đột biến trên gen $O T C$ là nguyên nhân gây bệnh thiếu hụt OTC, một trong các bệnh UCD phổ biến nhất với tỷ lệ ước tính khoảng 1/77.000 1/62.000 [21]. Đến nay, cơ sở dữ liệu Clinvar đã cập nhật 642 đột biến gây bệnh trên gen OTC. Phần lớn các đột biến được tìm thây ở bệnh nhân mắc bệnh thiếu hụt OTC là đột biến điểm. Trong đó, đột biến sai nghĩa chiếm tỷ lệ lớn nhất (84\%), sau đó đến đột biến vô nghĩa, mất hoặc xen đoạn nhỏ.

Năm 2016, nhóm nghiên cứu của Qin đã sử dụng NGS để sàng lọc đột biến trên gen $O T C$ ở 175 gia đình. Kết quả đã phát hiện được 1 đột biến thể khảm c.386 +1G>T ở bệnh nhân nam 19 tuổi và 1 đột biến thể thay thế, dạng dị hợp tử c.1046T >C (p.L349P) ở bé gái 7 tuổi trên gen OTC [22]. 1 đột biến xen đoạn nhỏ tại vị trí mối nối, thể đồng hợp tử c. $298+5 \mathrm{G}>\mathrm{C}$ trên gen $O T C$ cũng được xác định là nguyên nhân gây bệnh thiếu hụt OTC ở 1 bệnh nhân trong nghiên cứu của Park và cộng sự (2016) [23]. Phương pháp giải trình tự gen thế hệ mới cũng được áp dụng thành công để phát hiện đột biến gây bệnh trên 3 bé gái người Thái Lan có biểu hiện không kiểm soát được hành vi, suy gan cấp tính, bệnh não [20]. Hai đột biến thể mới, thể dị hợp tử trên gen $O T C$ bao gồm 1 đột biến dịch khung đọc (c.209 210delAA, p.K70Rfs*17) và 1 đột biến thay thế (c.850T>A, p.Y284N) ở bệnh nhân 1 và 3 . Một đột biến dị hợp tử đã được công bố 482A $>\mathrm{G}$ (p.N161S) được ghi nhận ở bệnh nhân 2 [24]. Các kết quả lâm sàng, sinh hóa và sàng lọc di truyền là cơ sở để xác nhận 3 bệnh nhân mắc bệnh thiếu hụt OTC [24]. Trong số 10 đột biến được tìm thấy trên gen $O T C$ và $C P S 1$ ở 9 bệnh nhân Trung Quốc chẩn đoán UCD khởi phát sơ sinh bằng giải trình tự toàn bộ vùng exon có 1 đột biến mới (c.176T>C, p.L59P), và 6 đột biến đã được ghi nhận (c.119G $>A$, p.R40H; c.540G $>$ C,$\quad$ p.Q180H; c.803T $>$ C, p.M268T; c.626C $>$ T, p.A209V; c.626C $>$ T, p.A209V) trên gen $O T C$ [15]. Nghiên cứu của Olga và cộng sự (2021) sử dụng phương pháp WES đã phát hiện được 1 đột biến dịch khung mới, c.78-1G $>\mathrm{A}$, trên exon 2 , gen $O T C$ làm mất
$1 \mathrm{bp}$ và dịch chuyển khung đọc c.78delG (p.C27Vfs*11) ở bé gái, 4 tuổi với các triệu chứng như, từ chối ăn thịt, rối loạn thần kinh, chậm nói, nồng độ ala-ninefminotransferase (ALT), aspartate aminotransferase (AST) tăng gấp 10 lần. Đột biến này cũng được tìm thấy ở trạng thái dị hợp tử trên bố bệnh nhân, nhưng không biểu hiện triệu chứng [21].

\subsection{NGS phát hiện đột biến trên gen NAGS1}

$\mathrm{N}$-acetylglutamate synthase (NAGS) xúc tác cho phản ứng kết hợp glutamate và acetylCoA tạo N-acetylglutamate (NAG). NAG là chất hoạt hóa allosteric của CPS1. Gen mã hóa cho NAGS, nằm trên cánh dài của nhiễm sắc thể 17 tại vị trí 17q21.31. Các đột biến trên gen $N A G S$ dẫn đến sự thiếu hụt NAG và sai hỏng CPS1. Đây chính là nguyên nhân làm cho phản ứng chuyển đổi amoniac thành carbamoylphosphate không thực hiện được do vắng mặt của $\mathrm{NAG}$, gây bệnh thiếu hụt NAGS. Thiếu NAGS là rối loạn di truyền lặn trên nhiễm sắc thể thường siêu hiếm với tỷ lệ mắc khoảng 1/7.000.000- 1/3.500.000 [25]. Năm 1981, bệnh này lần đầu tiên được mô tả ở một trẻ sơ sinh tăng amoniac máu nhưng không phát hiện được hoạt tính NAGS ở mô gan [25]. Năm 2002 , nhờ vào việc xác định gen $N A G S$, các đột biến trên gen này đã được phát hiện. Năm 2016, số liệu ghi nhận 59 bệnh nhân mắc bệnh thiêu hụt NAGS, ở 45 gia đình, đã được xác nhận ở mức độ di truyền phân tử [25]. Năm 2020, từ 48 bài báo được công bố, Kennenson và Singh (2020) đã thống kê được 98 trường hợp mắc bệnh ở 79 gia đình [26]. Đến nay, 83 đột biến gây bệnh trên gen NAGSI được cơ sở dữ liệu ClinVar ghi nhận. Phương pháp giải trình tự gen thế hệ mới chưa được sử dụng phổ biến để phát hiện đột biến trên gen này.

\subsection{NGS phát hiện đột biến trên gen ASS1}

Argininosuccinate synthetase (ASS1) xúc tác cho phản ứng kết hợp giữa citrulline và aspartate tạo ra argininosuccinate trong tế bào chất của các tế bào gan. Gen $A S S 1$ nằm trên cánh dài của nhiễm sắc thế số 9 tại vị trí $9 \mathrm{q} 34.1$, có kích thước $63 \mathrm{~kb}, 16$ exon, trong đó quá trình 
dịch mã bắt đầu từ exon 3 , mã hóa cho chuỗi popypeptide gồm 412 amino acid [27]. Cơ sở dữ liệu Clinvar đã cập nhật 255 đột biến trên gen ASS1 gây bệnh Citrullinemia typ 1. Bằng công nghệ WES, nhóm nghiên cứu của Constantinos Pangalos (2016) đã thực hiện phân tích trên 758 gen liên quan đến các rối loạn di truyền ở 14 phôi có các biểu hiện bất thường qua khám siêu âm trước sinh. Kết quả đã phát hiện được đột biến ở 6 phôi, trong đó, 3 trường hợp mang các đột biến liên quan đến hội chứng Ellis-van Creveld, hội chứng Ehlers-Danlos và bệnh cơ Nemaline 2 bị đình chỉ thai kỳ, 3 trường hợp còn lại mang các đột biến liên quan đến bệnh Citrullinemia, hội chứng Noonan, hội chứng Kallmann liên quan đến PROKR2. Hai biến thế, đồng hợp tử c.725C $>\mathrm{T}$, p.T242I; c.971G $>\mathrm{T}$, p.G324V trên gen $A S S 1$ đã được xác định, có thể là nguyên nhân của các dấu hiệu bất thường não khi chụp cộng hưởng và là cơ sở để chẩn đoán bệnh Citrullinemia ở thai nhi, 23 tuần tuổi [28]. Tiến hành sàng lọc bằng WES trong 1 gia đình người Trung Quốc, có 1 thành viên được chẩn đoán mắc bệnh Citrullinemia typ 1, Lin và cộng sự (2019) đã xác định được 1 đột biến tại vị trí mối nối, thể đồng hợp tử, c. $773+4 \mathrm{~A}>\mathrm{C}$ và được di truyền từ bố và mẹ [27]. Kết quả này là cơ sở để hiểu rõ mối tương quan giữa kiểu gen và kiểu hình của bệnh Citrullinemia typ 1 trong cộng đồng người Trung Quốc [23].

\subsection{NGS phát hiện đột biến trên gen SLC25A13}

Gen SLC25A13 mã hóa cho protein citrin, hoạt động như 1 protein vận chuyển aspartate glutamate xuyên màng ty thể. Gen SLC25A13, nằm trên cánh dài của nhiễm sắc thể số 7 tại vị trí 7q21.3 gồm 18 exon và 17 intron [29]. Cơ sở dữ liệu Clinvar đã cập nhật 233 đột biến gây bệnh trên gen $S L C 25 A 13$. Các đột biến trên gen này làm mất hoạt động của citrin, do đó, quá trình vận chuyển aspartate từ ty thể sang tế bào không thực hiện được. Điều này làm aspartate không có mặt để tham gia vào phản ứng chuyển đổi citrulline thành argininosuccinate với sự xúc tác của argininosuccinate synthetase. Đây là nguyên nhân gây bệnh thiếu hụt citrin hay còn gọi là Citrullinemia typ 2.

Trong những năm gần đây, công nghệ giải trình tự thế hệ mới được sử dụng rộng rãi trong việc phát hiện đột biến trên gen SLC25A13. Năm 2014, Liu và cộng sự đã giải trình tự 5,63 $\mathrm{kb}$ các vùng mã hóa và vùng không mã hóa tiếp giáp của gen $S L C 25 A 13$ bằng hệ thống HiSeq2000 (Illumina) và phát hiện được 1 đột biến đã công bố c.1177+1G $>\mathrm{A}$ và 1 đột biến mới c. 754G $>$ A (p.E252K) ở 1 bé gái Trung Quốc, 5 tháng tuối đã được chẩn đoán mắc thiếu hụt citrin thông qua phân tích lâm sàng và hóa sinh [29]. Bằng phương pháp giải trình tự gen đích, nhóm nghiên cứu của Togawa (2016) đã sàng lọc 109 trẻ sơ sinh có mẹ mắc bệnh ứ mật thai kỳ và xác định được 5 bệnh nhân mang các đột biến dị hợp tử trên gen $S L C 25 A 13$ [30]. Từ 269 mẫu máu có kết quả dương tính với các xét nghiệm sàng lọc sơ sinh của 120.700 trẻ sơ sinh, nhóm nghiên cứu Hàn Quốc đã sàng lọc trên 97 gen để phát hiện các bệnh chuyển hóa di truyền. Trong số 45 đột biến được công bố, đột biến c.851delGTAT (p.M285Pfs*2) trên gen $S L C 25 A 13$, dạng dị hợp tử được phát hiện là nguyên nhân gây bệnh Citrullinemia typ 2 ở 2 bệnh nhân [23]. Berna Şeker-Yılmaz và cộng sự (2017) đã sử dụng công nghệ giải trình tự gen thế hệ mới của Illumina để phát hiện 1 đột biến thay thế, dạng đồng hợp tử (c.1354G $>$ A, p.V452I) trên gen SLC25A13 ở bé trai Thổ Nhĩ Kỳ, 3 tháng tuổi, được chẩn đoán thiếu hụt citrin [31]. Phương pháp giải trình tự vùng mã hóa được sử dụng để phát hiện đột biến c.1610_1612delinsAT, ở bé trai 13 tuồi, trong 1 gia đình Ần Độ có hôn nhân cận huyết, với các triệu chứng mê sảng tái phát, rối loạn giấc ngủ, tăng amoniac máu [32]. Xu J và cộng sự (2018) đã sử dụng công nghệ NGS để giải trình tự gen $S L C 25 A 13$ và sàng lọc được 8 đột biến trong đó có 2 đột biến mới (c.1357A>G \& c.1663dup23) ở 5 bệnh nhân người Trung Quốc. Nhóm tác giả cũng đã xác nhận đột biến c.851del4 và c.16381660dup là các đột biến phổ biến trên gen này [33]. 
Chương trình sàng lọc sơ sinh ở Trung Quốc đã thực hiện phân tích 573 gen liên quan đến các rối loạn di truyền nguy hiểm bằng WES trên 1127 trẻ sơ sinh. Số liệu phân tích ghi nhận SLC25A13 là 1 trong 5 gen có tần suất mang đột biến cao nhất [34]. Cũng bằng công nghệ này, chương trình sàng lọc sơ sinh bổ sung trong cộng đồng dân cư khu vực Tây Bắc, Trung Quốc, giai đoạn từ 20142019, đã tiến hành sàng lọc trên 14615 trẻ sơ sinh, phát hiện được 61 bệnh nhân mắc bệnh rối loạn chuyển hóa bẩm sinh. Trong số các đột biến được công bố, có 1 đột biến mất đoạn, dạng dị hợp tử trên gen $S L C 25 A 13$ (c.852 855del), 1 đột biển vô nghĩa trên gen $O T C$ (c.958C $>$ T, p.R320X), 1 đột biến thay thế và 1 đột biến vô nghĩa trên gen $A S L$ (c.206A>G, p.K69R; c.637C>T, p.R213X) [35]. Nghiên cứu của Liu và cộng sự (2021) khi sàng lọc đột biến ở 5 bệnh nhân UCD cũng đã phát hiện được 2 đột biến, dị hợp tử trên gen SLC25A13 bao gồm c.852_855delTATG, c.1021+1G $>$ A trong đó đột biến c.1021+1G>A là phát hiện mới [20].

\subsection{NGS phát hiện đột biến trên gen $A S L$}

Gen $A S L$ mã hóa cho argininosuccinate lyase, xúc tác cho phản ứng chuyển hóa argininosuccinate thành arginine và fumarate. Các đột biến trên gen này là nguyên nhân gây ra bệnh thiếu hụt ASL hay còn goi argininosuccinic niệu. Đây là loại bệnh phổ biến thứ hai trong nhóm các bệnh UCD với tỷ lệ mắc ước tính khoảng 1/70.000 [36]. Đến nay (3/2021), cơ sở dữ liệu Clinvar đã cập nhật 209 đột biến trên gen $A S L$.

Năm 2016, Wei Wen và cộng sự đã kết hợp phương pháp giải trình tự gen thế hệ mới và phương pháp bẫy exon (exon trapping) để sàng lọc và phát hiện được 1 đột biến mới c.434A $>\mathrm{G}$ (p.D145G) và 1 đột biến đã được công bố c.1366C > T (p.R456W) trên gen $A S L$ ở 1 bệnh nhân Trung Quốc, mắc bệnh argininosuccinic niệu [36]. Đặc biệt, bằng công nghệ giải trình tự toàn bộ vùng mã hóa, nhóm nghiên cứu của Ganetzky (2017) đã sàng lọc được 2 đột biến đã được công bố c.765dupG; p.M256Dfs*79 và c.1135C > T; p.R379C trên gen $A S L$ ở 1 bé trai 26 tháng tuổi ở New Jersey có kết quả sàng lọc sơ sinh bình thường [37]. 1 đột biến thay thế mới c.206A>G, p.K69R và 1 đột biến mất bộ ba kết thúc đã công bố (c.637C >T, p.R213*) ở bé trai, 23 tháng tuổi, người Trung Quốc đã được Zhao và cộng sự (2019) phát hiện bằng công nghệ WES [38]. Năm 2020, Osawa và cộng sự đã báo cáo 2 đột biến thể dị hợp tử c.91G $>A$ (p.D31N) và c.1251-1G>C ở bé trai 14 tuổi, mắc bệnh argininosuccinic niệu khởi phát muộn [39]. Bằng phương pháp này, 10 biến thể trên 4 gen $A S L, C P S 1, O T C$ và $S L C 25 A 13$ đã được Liu và cộng sự (2021) phát hiện ở 5 gia đình trong đó có 2 đột biến trên gen $A S L$ bao gồm c.311C $>\mathrm{T}$ (p. R111W) và c.630_646del [20].

\subsection{NGS phát hiện đột biến trên gen ARG1}

Arginase 1 (ARG1) xúc tác cho phản ứng thủy phân arginine thành ornithine và urê, là phản ứng cuối cùng trong chu trình chuyển hóa urê. Các đột biến trên gen ARG1 làm sai hỏng hoạt động của $A R G 1$ và là nguyên nhân của bệnh thiếu hụt Arginase 1, loại bệnh ít phổ biến nhất trong các bệnh UCD. Cơ sở dữ liệu Clinvar đã cập nhật 101 đột biến trên gen $A R G 1$. Sử dụng công nghệ giải trình tự gen thế hệ mới, Yucel và cộng sự vào năm 2018 đã sàng lọc được 1 đột biến dịch khung đọc, thể đồng hợ tư c.703 707delGGACTinsAGACTGGACC (p.G235Rfs*20) ở bệnh nhân mắc bệnh thiếu hụt arginase 1 với các biểu hiện động kinh co giật không tái phát và suy gan [40]. Nhóm nghiên cứu của Elsayed, L. E. O. (2020) đã tiến hành phân tích vùng mã hóa của 5 bệnh nhân, ở một gia đình người Sudan có mối quan hệ cận huyết với các biểu hiện điển hình như liệt tứ chi, chậm phát triển về trí tuệ. Kết quả đã sàng lọc được 1 đột biến thay thế, dạng đồng hợp tử mới c.458T >A, p.V153E trên gen $A R G 1$ [41].

\subsection{NGS phát hiện đột biến trên gen SLC25A15}

Quá trình vận chuyển ornithine từ tế bào chất đến chất nền ty thể và vận chuyển citrulline từ ty thể vào tế bào chất được thực hiện nhờ 
protein vận chuyển ORNT1. Gen mã hóa cho protein ORNT1, SLC25A15, nằm trên cánh dài của nhiễm sắc thể 13 tại vị trí 13q14, gồm 7 exon, mã hóa cho chuỗi polypeptide dài 301 amino acid [42]. Các đột biến trên gen SLC25A15 gây ra bệnh thiếu hụt ornithine translocase hay còn gọi là hội chứng $\mathrm{HHH}$ (Hyperornithinemia-hyperammonemiahomocitrullinuria), chiếm tỷ lệ khoảng 1,0 - 
Bảng 2. Môt số đột biến trên các gen liên quan đến bệnh UCD được phát hiện bằng NGS.

\begin{tabular}{|c|c|c|c|c|c|}
\hline Gen & Đột biến & TLTK & Gen & Đột biến & TLTK \\
\hline \multirow[t]{27}{*}{ CPS1 } & c.580C > T, p.Q194* & {$[14]$} & \multirow[t]{12}{*}{ OTC } & c. $298+5 \mathrm{G}>\mathrm{C}$ & [23] \\
\hline & c. 1547 delG, p.G516Afs $* 5$ & {$[14]$} & & $\begin{array}{l}\text { c.209_210delAA, } \\
\text { p.K70Rfs*17 }\end{array}$ & {$[24]$} \\
\hline & c. $2537 \mathrm{C}>\mathrm{T}$, p.P846L & [17] & & c. $850 \mathrm{~T}>\mathrm{A}, \mathrm{p} . \mathrm{Y} 284 \mathrm{~N}$ & [24] \\
\hline & c. $3443 \mathrm{~T}>\mathrm{A}, \mathrm{p} . \mathrm{M} 1148 \mathrm{~K}$ & [17] & & $482 \mathrm{~A}>\mathrm{G}, \mathrm{p} . \mathrm{N} 161 \mathrm{~S}$ & [24] \\
\hline & c. $1799 \mathrm{G}>\mathrm{A}$, p.C600Y & [17] & & c.176T $>$ C, p.L59P & [15] \\
\hline & $\begin{array}{c}\text { c.4088_4099del, p.L } \\
1363 \text { I1366del }\end{array}$ & {$[17]$} & & c. $119 \mathrm{G}>\mathrm{A}, \mathrm{p} . \mathrm{R} 40 \mathrm{H}$ & [15] \\
\hline & c.1981G>T, p.G661C & {$[18]$} & & c. $540 \mathrm{G}>\mathrm{C}, \mathrm{p} . \mathrm{Q} 180 \mathrm{H}$ & [15] \\
\hline & c. $2896 \mathrm{G}>\mathrm{T}$, p.E966* & [18] & & c. $803 \mathrm{~T}>\mathrm{C}, \mathrm{p} . \mathrm{M} 268 \mathrm{~T}$ & [15] \\
\hline & c. $622-3 \mathrm{C}>\mathrm{G}$ & [18] & & c. $626 \mathrm{C}>\mathrm{T}$, p.A209V & [15] \\
\hline & c. $1631 \mathrm{C}>\mathrm{T}, \mathrm{p} . \mathrm{T} 544 \mathrm{M}$ & [18] & & c. $626 \mathrm{C}>\mathrm{T}$, p.A209V & [15] \\
\hline & c. $2938 \mathrm{G}>\mathrm{A}, \mathrm{p} . \mathrm{G} 980 \mathrm{~S}$ & {$[15]$} & & $\begin{array}{c}\text { c.78-1G }>\text { A, c. } 78 \mathrm{delG}, \\
\text { p.C27Vfs*11 }\end{array}$ & {$[21]$} \\
\hline & c.3734T $>$ A, p.L1245H & {$[15]$} & & c. $958 \mathrm{C}>\mathrm{T}, \mathrm{p} . \mathrm{R} 320 \mathrm{X}$ & {$[35]$} \\
\hline & c.2162G $>$ A, p.R721Q & {$[15]$} & \multirow[t]{10}{*}{ SLC25A13 } & c. $1177+1 \mathrm{G}>\mathrm{A}$ & [29] \\
\hline & c. $3784 \mathrm{C}>\mathrm{T}, \mathrm{p} . \mathrm{R} 1262 \mathrm{X}$ & {$[15]$} & & c. $754 \mathrm{G}>\mathrm{A}$, p.E252K & [29] \\
\hline & c. $478 \mathrm{G}>$ A, p.A160T & [19] & & $\begin{array}{l}\text { c.851delGTAT, } \\
\text { p.M285Pfs*2 }\end{array}$ & [23] \\
\hline & c.3949C $>$ T, p.R1317W & [19] & & c.1354G $>$ A, p.V452I & [31] \\
\hline & c. $3945 \mathrm{G}>$ A, p.W1315X & [19] & & c.1610_1612delinsAT & [32] \\
\hline & c.1958T $>$ G, p.V653G & [19] & & c. $1357 \mathrm{~A}>\mathrm{G}$ & [33] \\
\hline & c. $1271 \mathrm{~A}>\mathrm{T}$, p.E379V & [19] & & c.1663dup23 & [33] \\
\hline & c. $3928 \mathrm{C}>\mathrm{T}, \mathrm{p} . \mathrm{P} 1265 \mathrm{~S}$ & [19] & & c. $852 \_855 \mathrm{del}$ & [35] \\
\hline & c. $1760 \mathrm{G}>\mathrm{A}$, p.R587H & [19] & & c.852_855delTATG & {$[20]$} \\
\hline & c. $1145 \mathrm{C}>\mathrm{T}$, p.P382L & [19] & & c. $1021+1 \mathrm{G}>\mathrm{A}$ & {$[20]$} \\
\hline & $\begin{array}{c}\text { c. } 2865 \text { c. } 2869 \mathrm{delAAACT}, \\
\text { p.T955Tfs }\end{array}$ & [19] & \multirow[t]{13}{*}{$A S L$} & c. $434 \mathrm{~A}>\mathrm{G}, \mathrm{p} . \mathrm{D} 145 \mathrm{G}$ & [36] \\
\hline & c. $2429 \mathrm{~A}>\mathrm{C}, \mathrm{p} . \mathrm{Q} 810 \mathrm{P}$ & {$[20]$} & & c. $1366 \mathrm{C}>\mathrm{T}, \mathrm{p} . \mathrm{R} 456 \mathrm{~W}$ & {$[36]$} \\
\hline & c. $2876 \mathrm{~A}>\mathrm{G}$, p. Y959C & {$[20]$} & & $\begin{array}{c}\text { c.765dupG; } \\
\text { p.M256Dfs*79 }\end{array}$ & {$[37]$} \\
\hline & 2339G $>$ A, p.R780H & {$[20]$} & & c.1135C $>$ T; p.R379C & [37] \\
\hline & c. $3520 \mathrm{C}>\mathrm{T}, \mathrm{p} . \mathrm{R} 1174 \mathrm{X}$ & [20] & & c. $206 \mathrm{~A}>\mathrm{G}$, p.K69R & [38] \\
\hline \multirow[t]{3}{*}{$A S S 1$} & c. $725 \mathrm{C}>\mathrm{T}, \mathrm{p} . \mathrm{T} 242 \mathrm{I}$ & [28] & & c. $637 \mathrm{C}>\mathrm{T}, \mathrm{p} . \mathrm{R} 213 *$ & [38] \\
\hline & c. $971 \mathrm{G}>\mathrm{T}, \mathrm{p} . \mathrm{G} 324 \mathrm{~V}$ & [28] & & c. $91 \mathrm{G}>$ A, p.D31N & [39] \\
\hline & c. $773+4 \mathrm{~A}>\mathrm{C}$ & [27] & & c. $1251-1 \mathrm{G}>\mathrm{C}$ & [39] \\
\hline \multirow[t]{2}{*}{$A R G 1$} & $\begin{array}{c}\text { c.703_707delGGACTinsAGACTG } \\
\text { GACC, p.G235Rfs*20 }\end{array}$ & {$[40]$} & & c. $311 \mathrm{C}>\mathrm{T}, \mathrm{p} . \mathrm{R} 111 \mathrm{~W}$ & {$[20]$} \\
\hline & c. $458 \mathrm{~T}>\mathrm{A}, \mathrm{p} . \mathrm{V} 153 \mathrm{E}$ & [41] & & c.630_646del & {$[20]$} \\
\hline SLC25A15 & c.446delG: p.S149Tfs*45 & {$[44]$} & & c.206A $>$ G, p.K69R & {$[35]$} \\
\hline \multirow[t]{2}{*}{ OTC } & c. $386+1 \mathrm{G}>\mathrm{T}$ & {$[22]$} & & c. $637 \mathrm{C}>\mathrm{T}, \mathrm{p} . \mathrm{R} 213 \mathrm{X}$ & [35] \\
\hline & c.1046T >C, p.L349P & {$[22]$} & & & \\
\hline
\end{tabular}

3,8\% các bệnh UCD [43]. Từ báo cáo lâm sàng đầu tiên được thực hiện vào cuối những năm 1960 [11], đến nay cơ sở dữ liệu ClinVar đã cập nhật 148 đột biến gây bệnh trên gen $S L C 25 A 15$.
Một số nghiên cứu đã chỉ ra rằng đột biến p.F188del phổ biến trong cộng đồng người Canada gốc Pháp tại Quebec, trong khi đột biến vô nghĩa p.R179X lại phổ biến trong cộng đồng 
người Nhật Bản [11]. Năm 2020, công nghệ WES được sử dụng để sàng lọc trên các gen liên quan đến các rối loạn thần kinh trong 83 gia đình người Plestinin và Ả rập gốc Isreal nghi ngờ rối loạn thần kinh di truyền. Kết quả đã xác định được 1 đột biến dịch khung, dạng đồng hợp tử (c.446delG: p.S149Tfs*45) ở hai chị em với các triệu chứng như viêm đa dây thần kinh, liệt cứng cơ, mất điều hòa tiểu não nhẹ [44].

Một số đột biến trên gen liên quan đến bệnh rối loạn chu trình chuyển hóa urê bằng phương pháp giải trình tự gen thế hệ mới được tồng hợp tại Bảng 2.

\section{Kết luận}

Với những ưu điểm vượt trội so với phương pháp giải trình tự Sanger, phương pháp giải trình tự gen thế hệ mới đã thu được nhiều thành tựu đáng kể, từ đó khẳng định được vai trò trong nghiên cứu di truyền bệnh rối loạn chu trình chuyển hóa urê nói riêng và bệnh di truyền nói chung. Ngoài ra, sự kết hợp của phương pháp giải trình tự gen thế hệ mới với phương pháp giải trình tự Sanger sẽ xây dựng nhiều quy trình xét nghiệm gen hiệu quả, nhanh và chính xác.

\section{Lò̀i cảm ơn}

Công trình này được thực hiện bằng sự hỗ trợ kinh phí của đề tài "Nghiên cứu biến đổi gen ở các bệnh nhân mắc một số hội chứng/bệnh hiếm gặp ở Việt Nam bằng công nghệ giải trình tự gen thế hệ mới”, thuộc Chương trình phát triển khoa học cơ bản trong lĩnh vực Hoá học, Khoa học sự sống, Khoa học trái đất và Khoa học biển giai đoạn 2017-2025, Viện Hàn lâm Khoa học và Công nghệ Việt Nam.

\section{Tài liệu tham khảo}

[1] N. A. Mew, K. L. Simpson, A. L. Gropman, B. C. Lanpher, K. A. Chapman, M. L. Summar, Urea Cycle Disorders Overview, GeneReviews ${ }^{\circledR}$ [Internet] Seattle
(WA): University of Washington, Seattle (2003 Updated 2017). PMID: 20301396, Bookshelf ID: NBK1217.

[2] W. L. Stone, H. Basit, G. B. Jaishankar, Urea Cycle Disorders, StatPearls Publishing (2021) PMID: 29493985, Bookshelf ID: NBK482363.

[3] F. Endo, T. Matsuura, K.Yanagita, I. Matsuda, Clinical Manifestations of Inborn Errors of the Urea Cycle and Related Metabolic Disorders during Childhood, J Nutr., Vol. 134, No. 6, 2004, pp. 1605S1609S. https://doi.org/10.1093/jn/134.6.1605S.

[4] K. Schwarze, J. Buchanan, J. M. Fermont, H. Dreau, M. W. Tilley, J. M. Taylor, P. Antoniou, S. J. L. Knight, C. Camps, M. M. Pentony, The Complete Costs of Genome Sequencing: A Microcosting Study in Cancer and Rare Diseases from a Single Center in The United Kingdom, Genet Med., Vol. 22, No. 1, 2020, pp. 85-94. https://doi.org/ 10.1038/s41436-019-0618-7.

[5] M. Choi, U. I, Scholl, W. Ji, T. Liu, I. R.Tikhonova, P. Zumbo, A. Nayir, A. Bakkaloğlu, S. Ozen, S. Sanjad, Genetic diagnosis by Whole Exome Capture and Massively Parallel DNA Sequencing, Proc Natl Acad Sci USA, Vol. 106, No. 45, 2009, pp. 19096-19101. https://doi.org/ 10.1073/pnas.0910672106.

[6] S. Morganti, P. Tarantino, E. Ferraro, P. D'Amico, G. Viale, D. Trapani, B. A. Duso, G. Curigliano, Role of Next-Generation Sequencing Technologies in Personalized Medicine, P5 eHealth: An Agenda for the Health Technologies of the Future, Springer International Publishing, 2020, pp. 125-154, https://doi.org/ 10.1007/978-3-030-27994-3_8.

[7] S. Behjati, P. S. Tarpey: What is Next Generation Sequencing? Arch Dis Child Educ Pract, Vol. 98, No. 6, pp.236-238.

http://dx.doi.org/10.1136/archdischild-2013-304340

[8] A. Grada, K. Weinbrecht, Next-generation Sequencing: Methodology and Application, eJIFCC Vol. 133, No. 8, 2013, pp. e11,

https://doi.org/ 10.1038/jid.2013.248.

[9] K. R. Kukurba, S. B. Montgomery, RNA Sequencing and Analysis, Cold Spring Harb Protoc., Vol. 11, 2015, pp. 951-969, https://doi.org/10.1101/pdb.top084970

[10] C. D. Resta, S. G. Albiati, P. Carrera, M. Ferrari, Nextgeneration Sequencing Approach for the Diagnosis of Human Diseases: Open Challenges and New Opportunities, eJIFCC, Vol. 29, 2018, pp. 11.

[11] V. Rüfenacht, J. Häberle, Mutation Analysis of Urea Cycle Disorders, Journal of Pediatric Biochemistry, Vol. 4, 2014, pp. 33-43. https://doi.org/ 10.3233/JPB-140104

[12] U. Finckh, A. Kohlschütter, H. Schäfer, K. Sperhake, J. P. Colombo, A. Gal, Prenatal Diagnosis of Carbamoyl 
Phosphate Synthetase I Deficiency by Identification of a Missense Mutation in CPS1, Human mutation, Vol. 12, No. 3, 1998, pp. 206-211.

https://doi.org/10.1002/(SICI)1098-

1004(1998)12:3<206::AID-HUMU8>3.0.CO;2-E

[13] L. E. Laróvere, C. J. Angaroni, S. L. Antonozzi, M. B. Bezard, M. Shimohama, R. Dodelson de Kremer, Citrullinemia Type I, Classical Variant. Identification of $A S S \sim$ p.G390R (c.1168G $>$ A) Mutation in Families of a Limited Geographic Area of Argentina: A Possible Population Cluster, Clinical Biochemistry, Vol. 42, No. 10, 2009, pp. 1166-1168.

https://doi.org/10.1016/j.clinbiochem.2009.03.024

[14] R. Choi, H. D. Park, M. Yang, C. S. Ki, S.Y. Lee, J. W. Kim, J. Song, Y. S. Chang, W. S. Park, Novel Pathogenic Variant (c.580C $>$ T) in the CPS1 Gene in a Newborn With Carbamoyl Phosphate Synthetase 1 Deficiency Identified by Whole Exome Sequencing, Ann Lab Med, Vol. 37, No. 1, 2017, pp. 58-62. https://doi.org/ 10.3343/alm.2017.37.1.58.

[15] Q. Zhou, H. Huang, L. Ma, T. Zhu, The Application of Next-Generation Sequencing (NGS) in Neonatal-Onset Urea Cycle Disorders (UCDs): Clinical Course, Metabolomic Profiling, and Genetic Findings in Nine Chinese Hyperammonemia Patients, BioMed Research International, 2020, 5690915, https://doi.org/10.1155/2020/5690915.

[16] U. Amstutz, G. Andrey-Zurcher, D. Suciu, R. Jaggi, J. Haberle, C. R. Largiader, Sequence Capture and Next-generation Resequencing of Multiple Tagged Nucleic Acid Samples for Mutation Screening of Urea Cycle Disorders, Clin Chem, Vol. 57, No. 1, 2011, pp. 102-111. https://doi.org/10.1373/clinchem.2010.150706.

[17] G. Zhang, Y. Chen, H. Ju, F. Bei, J. Li, J. Wang, J. Sun, J. Bu, Carbamoyl Phosphate Synthetase 1 Deficiency Diagnosed by Whole Exome Sequencing, J Clin Lab Anal, Vol. 32, No. 2, 2018, e22241. https://doi.org/10.1002/jcla.22241.

[18] C. Yang, C. Zhou, P. Xu, X. Jin, W. Liu, W. Wang, C. Huang, M. Jiang, X. Chen, Newborn Screening and Diagnosis of Inborn Errors of Metabolism: A 5-year Study in an Eastern Chinese Population, Clin Chim Acta, Vol. 502, 2020, pp. 133-138, https://doi.org/10.1016/j.cca.2019.12.022.

[19] L. Fan, J. Zhao, L. Jiang, L. Xie, J. Ma, X. Li, M. Cheng, Molecular, biochemical, and clinical analyses of five patients with carbamoyl phosphate synthetase 1 deficiency, J Clin Lab Anal., Vol. 34, No. 4, 2020, e23124, https://doi.org/10.1002/jcla.23124

[20] F. Liu, L. S. Bao, R. J. Liang, X. Y. Zhao, Z. Li, Z. F. Du, S. G. Lv, Identification of Rare Variants
Causing Urea Cycle Disorders: A Clinical, Genetic, and Biophysical Study, J Cell Mol Med., Vol. 25, No. 8, 2021, pp. 4099-4109, https://doi.org/10.1111/jcmm.16379.

[21] S. Olga, S. Natalia, B. Igor, C. Alena, Z. Ekaterina, R. Oksana, M. Zhanna, S. Nadezhda, P. Aleksander, A Novel Splice Site Mutation in OTC Gene of a Female with Ornithine Transcarbamylase Deficiency and Her Asymptomatic Mosaic Father, J Genet., Vol. 99, No. 1, 2020, pp. 29, https://doi.org/10.1007/s12041-020-11898.

[22] L. Qin, J. Wang, X. Tian, H. Yu, C. Truong, J.J. Mitchell, K.J. Wierenga, W.J. Craigen, V.W. Zhang, L.C. Wong, Detection and Quantification of Mosaic Mutations in Disease Genes by Next-Generation Sequencing, J Mol Diagn., Vol. 18, No. 3, 2016, pp. 446453. https://doi.org/10.1016/j.jmoldx.2016.01.002.

[23 ] K. J. Park, S. Park, E. Lee, J. H. Park, J. H. Park, H. D. Park, S. Y. Lee, J. W. Kim, A Population-Based Genomic Study of Inherited Metabolic Diseases Detected Through Newborn Screening, Ann Lab Med., Vol. 36, No. 6, 2016, pp. 561-572.

https://doi.org/10.3343/alm.2016.36.6.561.

[24] V. Chongsrisawat, P. Damrongphol, C Ittiwut, R Ittiwut, K Suphapeetiporn, V Shotelersuk, The Phenotypic and Mutational Spectrum of Thai Female Patients with Ornithine Transcarbamylase Deficiency, Gene, Vol. 679, 2018, pp. 377-381.

https://doi.org/10.1016/j.gene.2018.09.026.

[25] E. H. Al Kaabi, A. W. El-Hattab, NAcetylglutamate Synthase Deficiency: Novel Mutation Associated with Neonatal Presentation and Literature Review of Molecular and Phenotypic Spectra, Mol Genet Metab Rep., Vol. 8, 2016, pp. 94-98. https://doi.org/10.1016/j.ymgmr.2016.08.004.

[26] A. Kenneson, R. H. Singh, Presentation and Management of N-acetylglutamate Synthase Deficiency: A Review of the Literature, Orphanet $J$ Rare Dis., Vol. 15, No. 1, 2020, pp. 279, https://doi.org/10.1186/s13023-020-01560-z.

[27] Y. Lin, H .Gao, B. Lu, S. Zhou, T. Zheng, W. Lin, L. Zhu, M. Jiang, Q. Fu, Citrullinemia type I is Associated with a Novel Splicing Variant, c.773 + 4A > $\mathrm{C}$, a Case Report and Literature Review, BMC Med Genet, Vol. 20, No. 1, 2019, pp. 110. https://doi.org/10.1186/s12881-019-0836-5

[28] C. Pangalos, B. Hagnefelt, K. Lilakos, C. Konialis, First Applications of A Targeted Exome Sequencing Approach in Fetuses with Ultrasound Abnormalities Reveals an Important Fraction of Cases with Associated Gene Defects, PeerJ., Vol. 4, 2016, pp. e1955. https://doi.org/10.7717/peerj.1955. 
[29] G. Liu, X. Wei, R. Chen, H. Zhou, X. Li, Y. Sun, S. Xie, N. Zhu Qu, G. Yang, A Novel Mutation of The SLC25A13 Gene in a Chinese Patient with Citrin Deficiency Detected by Target Next-Generation Sequencing, Gene, Vol. 533, No. 2, 2014, pp. 547-553. https://doi.org/10.1016/j.gene.2013.10.021.

[30] T. Togawa, T. Sugiura, K. Ito, T. Endo, K. Aoyama, K. Ohashi, Y. Negishi, T. Kudo, R. Ito, A. Kikuchi, Molecular Genetic Dissection and Neonatal/Infantile Intrahepatic Cholestasis Using Targeted NextGeneration Sequencing, J Pediatr, Vol. 171, 2016, pp. 171-177,

https://doi.org/10.1016/j.jpeds.2016.01.006

[31] B. Seker-Yilmaz, D. Kor, G.Tumgor, S. Ceylaner, $\mathrm{N}$ Onenli-Mungan, p.Val452Ile Mutation of the SLC25A13 Gene in a Turkish Patient with Citrin Deficiency, Turk J Pediatr, Vol. 59, No. 3, 2017, pp. 311-314.

https://doi.org/10.24953/turkjped.2017.03.012.

[32] A. R. R. Devi, S. M. Naushad, SLC25A13 c.1610_1612delinsAT Mutation in an Indian Patient and Literature Review of 79 Cases of Citrin Deficiency for Genotype-Phenotype Associations, Gene, Vol. 668, 2018, pp. 190-195.

https://doi.org/10.1016/j.gene.2018.05.076.

[33] J. Xu, M. Gao, Y. Lyu, Y. Tang, X.Wei, L. Yang, K. Zhang, Y. Liu, Z. Gai, Analysis of SLC25A13 gene Mutations in Five Infants with Neonatal Intrahepatic Cholestasis Caused by Citrin Deficiency, Zhonghua Yi Xue Yi Chuan Xue Za Zhi, Vol. 35, No. 1, 2018, pp. 3438 ,

https://doi.org/10.3760/cma.j.issn.1003-9406.2018.01.007

[34] Z. Luo, Y. Sun, F. Xu, J. Guo, L. Li, Z. Lin, J. Ye, X. Gu, Y. Yu, A Pilot Study of Expanded Newborn Screening for 573 Genes Related to Severe Inherited Disorders in China: Results From 1,127 Newborns, Ann Transl Med., Vol. 8, No. 17, 2020, pp. 1058, https://doi.org/10.21037/atm-20-1147.

[35] R. Zhang, R. Qiang, C. Song, X. Ma, Y. Zhang, F. Li, R. Wang, W. Yu, M. Feng, L. Yang, Spectrum Analysis of Inborn Errors of Metabolism for Xpanded Newborn Screening in a Northwestern Chinese Population, Sci Rep., Vol. 11, No. 1, 2021, pp. 2699. https://doi.org/10.1038/s41598-021-81897-y.

[36] W. Wen, D. Yin, F. Huang, M. Guo, T. Tian, H. Zhu, Y. Yang, NGS in Argininosuccinic Aciduria Detects a Mutation (D145G) Which Drives Alternative Splicing of $A S L$ : a Case Report Study, BMC Med Genet, Vol. 17, 2016, pp. 9, https://doi.org/10.1186/s12881016-0273-7.
[37] R. D. Ganetzky, E. Bedoukian, M. A. Deardorff, C. Ficicioglu, Argininosuccinic Acid Lyase Deficiency Missed by Newborn Screen, JIMD Rep., Vol. 34, 2017, pp. 43-47. https://doi.org/10.1007/8904_2016_2.

[38] M. Zhao, L. Hou, H. Teng, J. Li, J. Wang, K. Zhang, L. Yang, Whole-Exome Sequencing Identified a Novel Compound Heterozygous Genotype in $A S L$ in a Chinese Han Patient with Argininosuccinate Lyase. Deficiency, Biomed Res Int., Vol. 201, 2019, 3530198. https://doi.org/10.1155/2019/3530198.

[39] Y. Osawa, A. Wada, Y. Ohtsu, K. Yamada, T. Takizawa, Late-onset Argininosuccinic Aciduria Associated with Hyperammonemia Triggered by Influenza Infection in an Adolescent: A Case Report, Mol Genet Metab Rep., Vol. 24, 2020, 100605. https://doi.org/10.1016/j.ymgmr.2020.100605.

[40] H. Yucel, C. S. Kasapkara, M. Akcaboy, E. Aksoy, G. E. Sahin, B. E. Derinkuyu, S. Senel, S. Ceylaner, Recurrent Hepatic Failure and Status Epilepticus: an Uncommon Presentation of Hyperargininemia, Metab Brain Dis., Vol. 33, No. 5, 2018, pp. 1775-1778. https://doi.org/10.1007/s11011-018-0281-8.

[41] L. E. O. Elsayed, I. N. Mohammed, A. A. A. Hamed, M. A. Elseed, M. A. M. Salih, A. Yahia, R. Abubaker, M. Koko, A. S. I. Abd Allah, M. I. Elbashir, Novel Homozygous Missense Mutation in the ARG1 Gene in a Large Sudanese Family, Front Neurol, Vol. 11, 2020, 569996.

https://doi.org/10.3389/fneur.2020.569996.

[42] N. E. Tunali, C. M. Marobbio, N. O. Tiryakioglu, G. Punzi, S. K. Saygili, H. Onal, F. Palmieri, A Novel Mutation in the SLC25A15 Gene in a Turkish Patient with HHH Syndrome: Functional Analysis of the Mutant Protein, Mol Genet Metab., Vol. 112, No. 1, 2014, pp. 25-29, https://doi.org/10.1016/j.ymgme.2014.03.002.

[43] T. Silfverberg, F. Sahlander, M. Enlund, M. Oscarson, M. Hardstedt, Late Onset HyperornithinemiaHyperammonemia-Homocitrullinuria Syndrome - How Web Searching by The Family Solved Unexplained Unconsciousness: A Case Report, J Med Case Rep., Vol. 12, No. 1, 2018, pp. 274.

https://doi.org/10.1186/s13256-018-1794-9.

[44] H. Hengel, R. Buchert, M. Sturm, T. B. Haack, Y. Schelling, M. Mahajnah, R. Sharkia, A. Azem, G. Balousha, Z. Ghanem, First-line exome sequencing in Palestinian and Israeli Arabs with neurological disorders is efficient and facilitates disease gene discovery, Eur J Hum Genet, Vol. 28, No. 8, 2020, pp. 1034-1043. https://doi.org/10.1038/s41431-020-0609-9. 